\title{
LETRAMENTO VISUAL AOS SUJEITOS DIGITAIS: APLICAÇÃO DO MÉTODO DEEP VIEWING NO ENSINO-APRENDIZAGEM DA LÍNGUA INGLESA
}

\author{
VISUAL LITERACY TO DIGITAL SUBJECTS: THE USE OF DEEP VIEWING \\ METHOD IN ENGLISH TEACHING AND LEARNING
}

\author{
Ana Patrícia Cavalcanti Queiroz ${ }^{1}$
}

\begin{abstract}
RESUMO: O principal objetivo deste artigo é descrever os benefícios da aplicação de recursos visuais no processo de ensino-aprendizagem da língua inglesa não apenas para o desenvolvimento linguístico dos nossos discentes, mas também o desenvolvimento, por meio do Letramento Visual, da criticidade, da capacidade de comunicação e expressão, tomando consciência do ambiente ao seu redor, dos diferentes pontos de vista, dos seus papéis enquanto cidadãos e humanos. Para tanto, abordamos as características do nativo/sujeito digital e sua tendência ao estilo de aprendizagem visual, bem como o Letramento Visual e o método Deep Viewing. Por fim, descrevemos duas experiências com a atividade criada pela professora-pesquisa, chamada Your opinion is important, e apresentamos os resultados de sua aplicação. Com base nos resultados obtidos, concluiu-se que o Letramento Visual é tão importante quanto o Letramento de Escrita e Leitura e que sua prática em nossas escolas é fundamental para a formação de cidadãos críticos, resistentes às manipulações visuais que os cercam e capazes de se comunicarem efetivamente.
\end{abstract}

PALAVRAS-CHAVE: Sujeitos digitais. Recursos visuais. Letramento Visual. Deep Viewing.

ABSTRACT: The main purpose of this article is to describe the benefits of using visual resources in the English teaching and learning process not only to our students' linguistic development but also to develop, by means of Visual Literacy, their criticism, communication and expression abilities and to make them aware of the environment, of the different points of view and of their role in society as citizens and humans. To achieve this goal, we presente some characteristics of the digital subjects/natives and the fact that one of their main learning style is the visual one. Besides, Visual Literacy the Deep Viewing method are discussed. We also describe two applications of the activity created by the researcher, called Your opinion is important, and then present the results of both application. Based on the results, we conclude that Visual Literacy is as important as Reading and Writing Literacy and that learning Visual Literacy at school is essencial to the formation of critical citizens that are resilient to the visual manipulation around them and that are able to communicate effectively.

KEYWORDS: Digital subjects. Visual resources. Visual Literacy. Deep Viewing.

\section{Considerações iniciais}

O Letramento Visual é caracterizado por Bamford (2003) como a habilidade não apenas de decodificar e interpretar com sucesso mensagens visuais, como também de codificar e compor comunicações visuais significativas. Tal habilidade precisa ser desenvolvida nos e pelos indivíduos de forma a fortalecer a criticidade, reduzindo assim a passividade frente aos textos visuais que os circundam continuamente.

O interesse pelo Letramento Visual surgiu antes da realização de qualquer estudo formal. De forma empírica, a atividade que será descrita neste artigo foi aplicada inicialmente pela

\footnotetext{
${ }^{1}$ Mestre em Letras - Estudos da Linguagem pela Universidade Federal do Amazonas - UFAM (2016). Especialista em Docência da Língua Inglesa pela Escola Superior Batista do Amazonas - ESBAM (2014). Graduada em Letras - Língua e Literatura Inglesa pela Universidade Federal do Amazonas - UFAM (2010). Técnica em Assuntos Educacionais do Instituto Federal do Amazonas (IFAM).E-mail: ana.cavalcanti@ifam.edu.br
} 
Volume 15 - Número 2 - ago/dez de 2020

professora-pesquisadora, sob o título de Your opinion is important (Sua opinião é importante), em uma escola de idiomas da cidade de Manaus para turmas de inglês básico. Porém, foi apenas durante a realização de sua dissertação de mestrado que ela descobriu haver uma conceituação para o que costumava fazer. Para além de habilidades linguísticas e da criticidade de seus discentes, ela descobriu que suas aulas também oportunizavam o desenvolvimento do Letramento Visual, por meio de uma versão do método Deep Viewing, proposto por Pailliotet (1994; 1999). Posteriormente, já ciente do conceito e do método, a professora-pesquisadora aplicou a mesma atividade com uma turma de inglês avançado em outra escola de idiomas. Dessa vez, com o objetivo de observar os benefícios de sua atividade especificamente para o desenvolvimento do Letramento Visual. Ambas experiências serão descritas neste artigo.

Nas próximas seções, abordaremos sucintamente o nativo/sujeito digital e sua tendência ao estilo de aprendizagem visual, o Letramento Visual e o método Deep Viewing. Por fim, descreveremos as duas experiências com a atividade Your opinion is important e apresentaremos os resultados de ambas aplicações.

Este artigo pode vir a beneficiar a comunidade acadêmica, principalmente docentes da língua inglesa, uma vez que aborda a teoria do Letramento Visual, de forma a enriquecer e facilitar o processo de ensino-aprendizagem da língua inglesa enquanto desenvolve a criticidade, a capacidade de se comunicar, se expressar e de se ver no mundo, tomando consciência do ambiente ao seu redor, dos diferentes pontos de vista, dos seus papéis enquanto cidadãos e humanos. Vale ressaltar, contudo, que este artigo também pode vir a beneficiar qualquer indivíduo que tenha interesse de aprimorar seu próprio nível de Letramento Visual e/ou de aplicá-lo em suas aulas de qualquer disciplina ou em outro setor, como o comercial.

\section{$2 \mathrm{O}$ sujeito digital}

O termo Nativo Digital foi introduzido por Marc Prensky, o qual indica que esses sujeitos nasceram e cresceram no mundo digital (PRENSKY, 2001). Dentre os Nativos Digitais, podemos citar a Gerações Y, Z e Alpha, as quais são constituídas por indivíduos nascidos entre 1981-1999, 2000-2009 e 2010-2024, respectivamente (REILLY, 2012; MCCRINDLE, 2014). Vale mencionar que, diferentemente do contexto estrangeiro, no Brasil, a Geração Y cresceu, e apenas a $\mathrm{Z}$ nasceu rodeada de Tecnologias da informação e comunicação (TICs) segundo Gabriel (2013). No intuito de justificar essa afirmação da autora supramencionada, Queiroz (2016) defende que o brasileiro começou a ter acesso às TICs em seu dia a dia por volta de 1994, quando foi publicada, no jornal O Estado de São Paulo, a matéria Computador chega nas casas para ficar, escrita por Barbara Kantrowitz.

Retornando às terminologias, chamaremos os indivíduos, sejam os digitalmente nativos ou imigrante, de Sujeitos Digitais. Justificamos essa decisão tanto pelas diferenças no nível quali-quantitativo de acesso às TICs comparando não apenas o Brasil ao contexto estrangeiro, mas também suas próprias regiões, estados e cidades, quanto pelo fato de que atualmente nossas universidades, escolas e cursos são predominantemente compostos por indivíduos de todas essas gerações que nasceram e/ou cresceram rodeados por TICs, mesmo que em diferentes níveis.

Diversas são as características dos sujeitos digitais. Dentre elas podemos citar:

a) Recebem informações de forma rápida (PRENSKY, 2001);

b) Preferem acesso randômico, como hipertextos (PRENSKY, 2001);

c) Trabalham melhor de forma coletiva, i.e. em network (PRENSKY, 2001);

d) Preferem rápida gratificação e frequentes recompensas (PRENSKY, 2001);

e) Sentem-se confortáveis com a tecnologia (REILLY, 2012); 
Volume 15 - Número 2 - ago/dez de 2020

f) Expressam-se criativamente de formas diferentes às das gerações anteriores (PALFREY; GASSER, 2008);

g) Possuem habilidade multitask (VEEN, VRAKKING, 2009; TAPSCOTT. 2009; PRENSKY, 2013);

h) Possuem alta capacidade para resolução de problemas (VEEN; VRAKKING, 2009).

As características supramencionadas não serão aprofundadas neste trabalho, devido a questões de delimitação. Contudo, poderão ser melhor compreendidas pelo leitor tanto em suas respectivas referências quanto na dissertação da Queiroz (2016), a qual descreve diversas características dos sujeitos digitais voltadas ao processo de ensino-aprendizagem e sugere dicas e estratégias aos docentes.

Além dessas características, enfatizamos que, conforme Tapscott (2009) e Veen \& Vrakking (2009), os sujeitos digitais são predominantemente visuais e sinestésicos. Eles aprendem melhor, portanto, por meio de atividades dinâmicas, de investigação e de descoberta, preferindo ver, fazer, tocar, tentar e investigar. Eles não possuem facilidade para ouvir longas explicações e tendem a observar, de acordo com Tapscott (2009), as imagens antes do texto escrito, não o oposto. $\mathrm{O}$ autor adiciona que a imersão digital provavelmente alterou o sistema visual dos sujeitos digitais, principalmente a velocidade de seus reflexos visuais.

Vale mencionar que, segundo Ross (1972), o estímulo visual é entendido antes de haver qualquer capacidade verbal na criança. No que tange aos sujeitos digitais, Bamford (2003) afirma que os sujeitos digitais procuram o processamento rápido de informações e que todos os dias, eles são cercados por informações visuais, por meio de iPods, vídeo games, celulares, dentre outros. Para Reilly (2012), a maioria dos sujeitos digitais aprendem mais facilmente por meio de representações visuais do que com grande quantidade de textos verbais.

\section{Letramento Visual}

Letramento caracteriza-se por, além de decodificar os elementos do texto, ter a capacidade de compreendê-lo, interpretá-lo, explicá-lo; a capacidade de se expressar com clareza e de forma eficaz; a capacidade de identificar e assimilar os sentidos presentes no texto, seja ele verbal ou não-verbal. Sendo assim, podemos definir o Letramento Visual, nas palavras de Bamford (2003), como a habilidade tanto de interpretar imagens do presente e do passado quanto de produzir imagens que comuniquem efetivamente uma mensagem aos ouvintes. Caracteriza-se também como a habilidade de ler e escrever a linguagem visual, incluindo a capacidade de decodificar e interpretar com sucesso mensagens visuais bem como de codificar e compor comunicações visuais significativas.

John Debes (1969) foi quem primeiramente levantou conceitos teóricos sobre Letramento Visual. Segundo Bamford (2003), o Letramento Visual envolve a interpretação do conteúdo visual, o exame do seu impacto social, a discussão do seu objetivo, do público e da propriedade, a avaliação da precisão, da validade e do valor das imagens, além da consciência acerca dos possíveis usos manipuladores e das implicações ideológicas das imagens.

Ainda conforme Bamford (2003), um indivíduo letrado visualmente é capaz de:

- Entender o assunto das imagens;

- Analisar e interpretar imagens para identificar o sentido dentro do contexto cultural em que a imagem foi criada e existe;

- Analisar a sintaxe das imagens, inclusive estilo e composição;

- Avaliar o mérito estético do trabalho;

- Avaliar o mérito do trabalho no que tange à propósito e público-alvo;

- Compreender a sinergia, a interação, a inovação, o impacto afetivo e/ou "sentir" a imagem. (BAMFORD, 2003, p. 1, tradução nossa). 
De acordo com Bamford (2003), o Letramento Visual pode ser desenvolvido de forma automática até certo ponto. Porém, esse aprendizado automático costuma constituir-se em Habilidades de Pensamento de Ordem Inferior, i.e. uma aprendizagem de nível básico, com pouca retenção e profundidade. Faz-se importante, portanto, o ensino do Letramento Visual, inclusive nas escolas, para desenvolver interpretações e associações mais profundas, com as Habilidades de Pensamento de Ordem Superior.

\subsection{A educação visual}

Considerando não apenas a importância de atender ao estilo de aprendizagem predominantemente sinestésico e visual dos nossos discentes-sujeitos digitais, é de suma importância que as escolas trabalhem para o desenvolvimento humano e integral desses sujeitos, com o objetivo de formar cidadãos críticos, resistentes às manipulações que os cercam e capazes de se comunicarem efetivamente. O Letramento Visual é um dos caminhos para a (trans)formação desses cidadãos. Além dos diversos benefícios já elencados neste estudo, adicionamos o seguinte: o Letramento Visual pode ser utilizado como um meio, uma ferramenta para a melhoria da alfabetização e do letramento textual/linguístico, seja na língua materna, seja numa estrangeira.

De acordo com Ross (1972), o uso da comunicação visual pode ser uma extensão da aprendizagem da linguagem verbal. Em seu artigo, é descrita a aplicação de atividades de fotografia numa escola particular, dos Estados Unidos, chamada Green Chimneys. Com apoio de empresas, a escola disponibilizou câmeras aos seus discentes e pediu que eles tirassem fotos ao longo de seus dias letivos e do dia a dia fora da escola. Tiradas as fotos, os discentes precisavam explicá-las aos professores e aos seus colegas de classe.

Durante as atividades, perceberam o crescente entusiasmo dos discentes pela atividade fotográfica, inclusive dos discentes mais tímidos e calados, os quais passaram a se comunicar com mais frequência e de forma mais efetiva. Observaram ao longo da experiência a melhoria nas habilidades comunicacionais dos discentes, uma maior consciência da natureza e do ambiente ao redor deles, melhoria do autoconceito e autoestima dos discentes, além de maior motivação acadêmica. Adicionalmente, identificaram que as fotografias tiradas eram reveladoras, pois indicavam o interesse e as preocupações das crianças. Conforme Ross (1972), as discussões e os comentários relacionados às fotos serviam como um apoio adicional aos professores que trabalhavam com as crianças, pois a experiência demonstrou como a fotografia serve como um instrumento útil para a comunicação e para se expressar.

Partindo da experiência descrita por Ross (1972), a qual indica, por meio de um tipo de atividade, os benefícios do Letramento Visual na aprendizagem da linguagem verbal da língua materna, defendemos que esses mesmos benefícios são identificados no processo de ensino-aprendizagem de línguas estrangeiras, tendo em vista os resultados linguísticos obtidos na aplicação da atividade Your opinion is importante em turmas de língua inglesa pela professora-pesquisadora.

Como mencionado na parte introdutória, a primeira aplicação da atividade supramencionada, realizada em uma turma de nível básico da língua inglesa, foi planejada sem a base teórica do Letramento Visual, com o objetivo de desenvolvimento da fluência na língua inglesa e de criticidade. Por mais que tal aplicação não tenha tido objetivos acadêmicos, acreditamos ser importante sua descrição neste artigo para fins introdutórios dos procedimentos metodológicos posteriormente adotados. 
Volume 15 - Número 2 - ago/dez de 2020

\section{Your opinion is important: primeira aplicação da atividade}

Em 2012, em uma escola de idiomas da cidade de Manaus, Amazonas, a professorapesquisadora identificou dificuldades na oralidade em seus discentes, além de inquietar-se com a aparente baixa criticidade apresentada. Essa turma era de nível básico e contava com nove discentes, cuja faixa etária variava entre 13 e 22 anos de idade.

A turma em questão era composta por indivíduos com diferentes personalidades, dentre elas, a mais predominante era a introvertida. Esses discentes raramente participavam das aulas e ainda mais raramente se comunicavam na língua materna e, dentro de seu nível, na línguaalvo.

Ciente da importância da aplicação de diferentes técnicas e métodos em suas aulas e de que a aprendizagem de uma língua pode ser facilitada quando utilizada com propósito e para se falar o que se deseja falar, a professora organizou uma apresentação de powerpoint com uma sequência de 35 imagens variadas para a atividade que chamou de Your opinion is important. Em sala, ela explicou aos seus discentes que eles iriam primeiramente descrever as imagens, dizendo o que viam com os olhos. Ela utilizava essa frase antes mesmo de tomar conhecimento da teoria. Em um segundo momento, eles iriam expressar, como a professora costumava dizer, o que viam com o coração e com a mente, i.e. o que eles sentiam, com o que eles relacionavam a imagem, se já tinham passado ou se conheciam alguém que tinha passado pelo o que a imagem representava, o que eles pensavam sobre o tema levantado, e assim por diante.

Considerando o nível básico da turma, antes de iniciar a atividade, os discentes praticaram uma lista de expressões que poderiam auxiliá-los no desenvolvimento de suas ideias, como: $I$ think... (Eu acho); I guess... (Eu acho); I agree (because)... (Eu concordo (porque)); I disagree (because)... (Eu discordo (porque)); I think so (Eu acho que sim); I don't think so (Eu acho que não).

Com a primeira aplicação da atividade, foi identificado que além dessas expressões, era necessário praticar os vocabulários específicos dos temas. Sendo assim, a professora elaborou uma lista de palavras que poderiam ser úteis para cada imagem e finalizou assim a construção da metodologia de sua atividade, a qual passou a ocorrer da seguinte maneira:

I - Discentes selecionavam um número de um a 35 (quantidade de slides na apresentação) e, consequentemente, selecionavam a imagem correspondente ao slide;

II - Discentes descreviam o que viam na imagem, por meio de brainstorming (chuva de ideias): quantidades, cores, roupas, características físicas, locais, nomes de objetivos, dentre outros itens;

III - Professora anotava todos os itens no quadro e, ao término, praticava o significado e a pronúncia das palavras menos conhecidas;

IV - Professora solicitava que os discentes conversassem em duplas sobre o que eles sentiam ao ver a imagem, o que eles acreditavam ser a mensagem da imagem, qual era a opinião deles sobre o tema e se eles conseguiam relacionar o tema a eles ou a alguém conhecido. Para essa fase, a professora os encorajava a falar utilizando os vocabulários e as estruturas gramaticais que conheciam, independentemente de precisão gramatical, sem preocupação com erros ou com complexidades linguísticas. Os discentes eram encorajados a falarem mesmo que por meio de frases curtas e/ou soltas.

$\mathrm{V}$ - Discentes conversavam em duplas, utilizando o pouco vocabulário que possuíam do tema e muitas vezes deslizavam para a língua materna ou pediam a tradução de palavras à professora;

VI - Professora auxiliava os discentes e observava seus diálogos, anotando as dificuldades apresentadas e os temas abordados pelos discentes;

$\mathrm{V}$ - Professora praticava com os discentes alguns pontos gramaticais ou de vocabulário que observou durante o diálogo em duplas; 
VI - Em seguida, professora apresentava as palavras relacionadas aos temas observados e praticava com seus discentes o significado, o uso e a pronúncia delas;

VII - Por fim, após a prática do novo vocabulário e ainda com o acesso às palavras, os discentes eram encorajados a, voluntária e individualmente, expressarem suas ideias para a turma e para a professora. Para essa etapa, as mesmas instruções da fase em duplas eram dadas: falar na língua-alvo, mesmo que de forma simples e com frases curtas;

VIII - Professora encorajava, nesta fase, que os demais discentes dissessem, voluntariamente, se concordavam ou não com a ideia apresentada, sempre de forma respeitosa, e que explicassem também suas opiniões;

IX - Na aula seguinte, a professora aplicava curtas atividades de prática e revisão dos vocabulários trabalhados.

Essa atividade foi aplicada em diferentes turmas, porém foi apenas nessa turma de nível básico que ela durou um semestre inteiro, com intervalo de uma ou, no máximo, três aulas. Vale ressaltar que suas primeiras aplicações duraram cerca de 30 minutos devido à necessidade de explicar seu funcionamento. Porém, após a familiarização, a mesma atividade passou a durar de 10 a 15 minutos.

Ainda no primeiro mês de aplicação da atividade, observou-se mudanças relevantes na fluência dos discentes, i.e. na fluidez e naturalidade em que falavam a língua inglesa. Os erros gramaticais e de pronúncia continuavam, as estruturas construídas pelos discentes em suas falas ainda eram simples e, muitas vezes, incompletas, o vocabulário ainda precisava de aprofundamento, porém as pausas nas falas tinham reduzido substancialmente, o que demonstrava a diminuição da insegurança dos discentes e o consequente desenvolvimento de sua fluência. Além da fluência, a professora também identificou que os discentes tímidos estavam se voluntariando com mais frequência para a expressão pública de suas opiniões.

No segundo mês, a interação aumentou, e os discentes já conseguiam criar frases mais completas e complexas, com vocabulário acima do nível esperado para a turma. A partir do terceiro mês, a parte de expressão pública de opiniões transformou-se, de forma natural, em uma atividade de conversação em grupo, pois os próprios discentes pediam as falas para concordar, discordar ou complementar as opiniões de seus colegas. Com essa transformação, a professora passou a encorajar e monitorar cuidadosamente o respeito aos momentos de falas para que não houvesse interrupções desrespeitosas.

Durante o processo de aplicação dessa atividade, foi possível testemunhar a melhoria na fluência, na precisão gramatical e na pronúncia dos discentes em língua inglesa, além de um vasto enriquecimento de seu vocabulário, o que corrobora Ross (1972) quanto aos benefícios da educação visual e do uso da comunicação visual para a aprendizagem da linguagem verbal.

Vale mencionar que, assim como ocorreu na escola Green Chimneys, com a aplicação de atividades de fotografia descrita por Ross (1972), os resultados linguísticos não foram os únicos alcançados com a atividade Your opinion is important: houve uma transformação comportamental nos discentes. Os laços entre eles foram estreitados sobremaneira, novas amizades foram construídas, os discentes tímidos tornaram-se ativos e participativos não apenas na atividade em questão, mas de forma geral. Houve, inclusive, interferência positiva no comportamento externo à sala de aula, conforme afirmações tanto dos discentes quanto de suas mães, como a suavização de quadro depressivo e de ansiedade de alguns dos discentes envolvidos na atividade. Podemos dizer, portanto, que para além de processos linguísticos, ocorreram processos de transformações sociais e emocionais durante a atividade Your opinion is important.

Partindo dessa experiência inicial, a professora-pesquisadora adotou permanentemente a atividade em suas aulas para adolescentes, jovens e adultos de todos os níveis da Língua Inglesa e pôde observar a repetição e a continuidade dos resultados positivos nos níveis linguísticos, comunicacionais, emocionais, comportamentais e sociais. 
Volume 15 - Número 2 - ago/dez de 2020

Como mencionado na parte introdutória deste artigo, passaram-se anos até que a pesquisadora aprendesse que sua atividade também poderia desenvolver o Letramento Visual, o que gerou a curiosidade epistemológica propulsora de suas pesquisas posteriores, sobre as quais abordaremos a seguir.

\section{Deep viewing a a atividade You opinion is important}

Com o objetivo de reaplicar a atividade Your opinion is important com base no Letramento Visual, passou-se à pesquisa bibliográfica, de natureza qualitativa, durante a qual identificou-se que a atividade possuía relação com o método Deep Viewing, introduzido por Pailliotet (1994; 1999).

O Letramento Visual pode ser desenvolvimento por meio de diversas atividades. Ross (1972), por exemplo, adotou atividades fotográficas. Bamford (2003) sugere gravar os discentes interpretando emoções; observar os pacotes dos supermercados com objetivo de identificar o que é real e o que manipulado ou criado, observando símbolos, logos e tipos de letras utilizados; criar um dicionário visual. Todas essas atividades têm em comum o desenvolvimento de uma maior compreensão e interpretação das imagens e do mundo ao nosso redor.

Nas palavras de Bamford (2003, p. 1, tradução nossa), o Letramento Visual é tanto o que vemos com os nossos olhos quanto o que "vemos" com a nossa mente. Essa afirmação nos remete ao método chamado Deep viewing, proposto por Pailliotet $(1994 ; 1999)$ e caracterizado por ela como um método para a análise e construção crítica da compreensão textual, bem como um método de pesquisa e de instrução, para a análise sistemática das imagens, para a compreensão dos conteúdos, processos e formas da comunicação visual, utilizado para a compreensão social dos textos visuais. Ainda de acordo com a autora (1999), esse método pode ser aplicado para análise de imagens, filmes, vídeos, comerciais, programas de computador, obras de arte, anúncios, livros didáticos, web sites, dentre outros.

Segundo Pailliotet (1999), o Deep Viewing é um processo estruturado por meio do qual os participantes primeiramente identificam elementos textuais e formas discursivas, exemplificados por ela como língua, som, imagens e estruturas. Em seguida, eles interpretam e respondem a tais elementos e formas por meio de uma variedade de transações, de forma a conectar textos com suas formas midiáticas e ambientes de letramento com seus próprios pontos de vista e com as realidades sociais vigentes e possíveis. O método consiste, portanto, de três níveis: "[...] Primeiramente, os participantes observam, identificam e descrevem elementos no texto. Em seguida, eles respondem e interpretam esses dados de diferentes formas. Por fim, eles realizam a avaliação e a aplicação seus resultados. [...]" (PAILLIOTET, 1999, p. 32, tradução nossa).

Cada um desses níveis é constituído por diferentes códigos, os quais podem ser completa ou parcialmente discutidos nas atividades. Eles são: ação e sequência; semes e formas; atores e discurso; proximidade e movimento; cultura e contexto; efeitos e processo. Considerando sua alta adaptabilidade, ainda segundo Pailliotet (1999), para a aplicação do método, os participantes podem realizar o deep viewing das seguintes formas:

I - individualmente, de forma que todos analisam todos os códigos;

II - parcialmente, com a análise de códigos selecionados;

III - colaborativamente, sendo os códigos divididos entre os membros do grupo; ou

IV - em aprendizagem cooperativa, em que cada grupo fica responsável por analisar um código.

Retomando aos níveis, no primeiro, os participantes são instruídos a observarem e a descreverem resumidamente apenas o que veem e/ou ouvem de forma literal, sem avaliações ou interpretações. 
Coletadas as informações, reconhecidas e descritas as características explicitamente presentes nas imagens, inicia-se o segundo nível, no qual os participantes fazem observações do que está ou não está explicitamente presente no texto não-verbal e vão se movimentando para níveis de inferência. Nesta fase, segundo Pailliotet (1999), eles expressam as ideias que a imagem os remetem, realizam comparações e contrastes, criam hipóteses, conectam informações elementos textuais, relacionam as informações com textos e com experiências passadas e atuais, identificam o objetivo e o público-alvo, evidenciam em que contextos sociais, históricos, culturais ou intelectuais o texto se encontra, identificam e descrevem suas estratégias de análise e expressam sentimentos e compreensão do texto visual.

De acordo com Pailliotet (1999), primeiramente, cada participante expressa uma observação baseada nos aspectos explícitos do texto, identificados no primeiro e no segundo níveis, percebendo o que está presente e o que está ausente. Em seguida, as observações movimentam-se a níveis mais profundos de inferência.

O terceiro nível, além de requerer maior inferência, constitui-se do processo de sintetizar, expandir, avaliar e aplicar informações e interpretações evidenciadas nos primeiros dois níveis. Pailliotet (1999) indica que nesse momento, os participantes expressam suas opiniões sobre a imagem, discutem como eles podem aplicar o que identificaram a outras situações/contextos ou a outros textos verbais ou não-verbais. Em adição, eles fazem comparações e associações com suas próprias experiência pessoais, expectativas, objetivos, sentimentos e conhecimentos. Conforme Pailliotet (1994), nesta etapa, eles também observam se a interpretação pode variar de acordo com a cultura dos intérpretes, se as pessoas e/ou objetos presentes na imagem adequam-se à mensagem transmitida por ela, se a imagem alcança seu propósito e se ela transmite ou não a mensagem de forma eficaz.

\subsection{Procedimentos metodológicos e reaplicação da atividade}

Para a reaplicação da atividade Your opinion is important, em 2015, a professorapesquisadora manteve os recursos e os procedimentos anteriormente adotados, utilizando a mesma seleção de imagens e respeitando a mesma sequência de desenvolvimento da atividade em sala de aula. Essa decisão deveu-se à intenção de comparar os resultados obtidos na primeira turma com aqueles da nova turma.

Diferentemente do primeiro momento, considerando que já havia sido identificado o benefício da atividade para fluência, precisão gramatical, vocabulário e pronúncia, o objetivo da aplicação da atividade passou a ser evidenciar se a atividade Your opinion is important desenvolvia o Letramento Visual. Por conseguinte, a pesquisadora selecionou sua turma de inglês avançado para que pudesse concentrar sua atenção na criticidade e na habilidade de interpretação e decodificação visual de seus discentes.

No que tange à aplicação do método Deep Viewing, decidiu-se adotar a análise parcial dos participantes, visto que não consideraria todos os códigos de cada nível. Isso não apenas devido à necessária redução da atividade para que pudesse ser aplicada durante o semestre letivo da turma, como também pela intenção da pesquisadora de manter a sequência o mais próximo possível de sua primeira aplicação. Adotou-se, portanto, com base em Pailliotet (1999), a seguinte sequência:

I - descrição literal: observações acerca do que aparece explicitamente na imagem;

II - interpretação: observações acerca da mensagem transmitida pela imagem, das ideias as quais ela os remete; contextualização; identificação dos elementos que evidenciam os resultados obtidos na interpretação;

III - avaliação: expressão de opiniões sobre a imagem e sobre os temas levantados; associação da imagem, dos temas e dos elementos levantados com suas próprias experiências, com as experiências de pessoas ao seu redor e com seus sentimentos. 
No primeiro dia, a imagem aleatoriamente escolhida pelos discentes foi a de uma coruja (FIGURA 1). Primeiramente, eles descreveram a imagem e, em seguida, expressaram o que entenderam da imagem e qual a mensagem ela os remeteu. Como resposta, um(a) aluno(a) afirmou que a imagem o(a) fazia lembrar que às vezes esquecemos de dar banho em nossos animais. Outro(a) disse que as pessoas precisam tomar mais cuidado com a pressão da mangueira quando dão banho em seus animais.

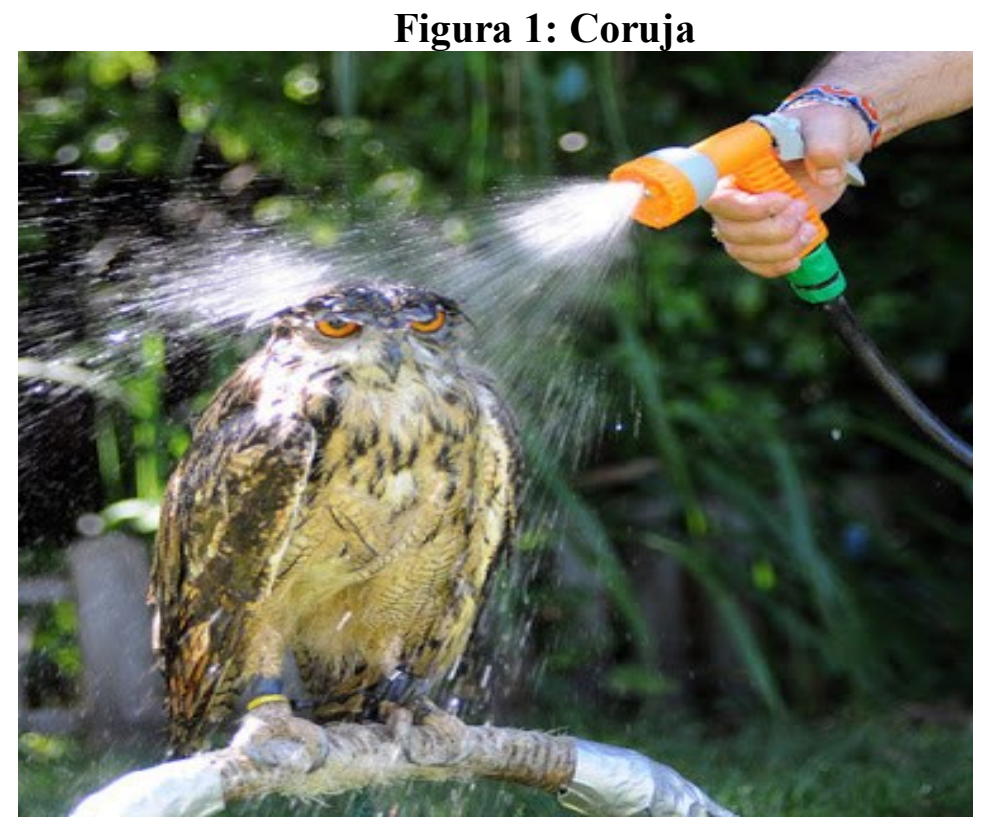

Fonte: http://arkhipelago.blogspot.com/2010/10/segunda-feira.html

As respostas dadas pelos discentes fortaleceram a hipótese da professora-pesquisadora, qual seja: muitos dos nossos discentes sabem ler uma imagem, mas não são necessariamente capazes de interpretá-la e de fazer associações partindo delas. Com o intuito de utilizar a atividade como instrumento de formação de cidadãos críticos e letrados visuais, a professora então perguntou se não relacionavam a imagem a alguma questão da sociedade ou com alguma experiência própria. Esse foi o ponto de ruptura. A partir de então os discentes relacionaram a imagem aos seguintes temas:

I - submissão no mercado de trabalho;

II - imposições da sociedade, como o padrão de beleza, as quais são contra a natureza de muitos, assim como o banho vai contra a natureza das aves;

III - bullying; e

IV - silêncio das vítimas devido ao medo.

Podemos afirmar, portanto, que presenciamos o Letramento Visual automático, a nível de Habilidades de Pensamento de Ordem Inferior, avançar, com apenas um ponto de ruptura promovido pela professora-pesquisadora, ao nível de Habilidades de Pensamento de Ordem Superior. Em outras palavras, observamos, nessa e nas diversas outras imagens trabalhadas posteriormente com a turma, o aprofundamento da interpretação das imagens e das associações realizadas, sejam culturais, históricas, linguísticas, sociais e pessoais. Concordamos, por conseguinte, com Bamford (2003) quando defende que o Letramento Visual precisa ser ensinado.

\section{Considerações finais}

Os benefícios dos recursos visuais no processo de ensino-aprendizagem de línguas estrangeiras são reconhecidos e amplamente estudados. Por outro lado, ainda há poucas 
pesquisas acerca da aplicação de atividades de aprofundamento do Letramento Visual, com objetivo de desenvolvimento linguístico, social, cultural e emocional dos nossos discentes.

Concordarmos com Ross (1972) quando diz que a intenção não é colocar um letramento como mais importante do que o outro. Portanto, não objetivamos neste trabalho dizer que o Letramento Visual é mais importante do que o letramento textual/linguístico, mas sim apresentá-lo como um dos caminhos que não deveriam ser ignorados na trilha educativa de nossos discentes. Defendemos, portanto, que o Letramento Visual deveria ter a mesma importância dos demais letramentos, que deveria estar inerente e profundamente incorporado na educação formal e informal de nossos filhos.

Por mais que nosso trabalho tenha se voltado muito mais ao Letramento Visual no ensinoaprendizagem de línguas estrangeiras, mais precisamente da língua inglesa, não podemos deixar de mencionar a importância de novos estudos e experiências para sua implementação em todas as áreas de conhecimento, considerando seus benefícios na resolução de problema, na criticidade e nas associações mentais.

\section{Referências}

BAMFORD, A. The visual literacy white paper. Austrália: Adobe Systems Pty Ltd, 2003. Disponível em: <https://www.aperture.org/wp-content/uploads/2013/05/visual-literacywp.pdf>. Acesso em: 22 ago. 2020.

GABRIEL, Martha. Educ@r: a (r)evolução digital na educação. São Paulo: Saraiva, 2013.

MCCRINDLE, M. The ABC of XYZ: Understanding the Global Generations. Australia: McCrindle Research Pty Ltd, 2014.

PAILLIOTET, A. W. Understanding Visual Information through Deep Viewing. In: BEAUCHAMP, Darrell G.; BRADEN, Roberts A.; BACA, Jusy Clark. Visual Literacy in the Digital Age. Blacksburg, VA: International Visual Literacy Association, 1994. p. 102-111. Disponível em: <https://archive.org/details/ERIC_ED370602/page/n125/mode/2up>. Acesso em: 22 ago. 2020.

PAILLIOTET, A. W. Deep Viewing: Intermediality in Preservice Teacher Education. In: Semali, L., Pailliotet, A. W. (Eds.), Intermediality: The teachers' handbook of critical media literacy Boulder, CO: Westview, 1999. p. 31 -52.

PRENSKY, M. Digital Natives, Digital Immigrants. On the Horizon. MCB University Press, Vol. 9 No. 5, October 2001.

QUEIROZ, A. P. C. Escolas do século XIX, professores do século XX e alunos do século XXI?: A subjetivação no discurso sobre a educação escolar. 120 f. 2016. Dissertação (Mestrado em Letras) - Universidade Federal do Amazonas, Manaus, 2016.

REILLY, P. Understanding and Teaching Generation Y. English Teaching Forum, n 1, p. 2$11,2012$.

ROSS, S. B. Jr. Visual Literacy activities in the schools. Brewster, NY: Green Chimneys School, 1972. Disponível em: <https://files.eric.ed.gov/fulltext/ED060656.pdf $>$. Acesso em: 23 ago. 2020.

TAPSCOTT, D. Grown up digital: how the Net Generation is changing your world. Nova York: Mc Graw Hill, 2009.

VEEN, W.; VRAKKING, B. Homo zappiens: educando na era digital. Tradução: Vinicius Figueira. Porto Alegre: Artmed, 2009. 